\title{
Therapeutic Apheresis in Acute Kidney Injury
}

VA Voinov $^{1^{*}}$, MG Kovalev ${ }^{2}$, KS Karchevsky ${ }^{1}$ and OV Isaulov ${ }^{1}$

${ }^{1}$ Apheresis Therapy Department, Pavlov First St. Petersburg State Medical University, Russia

${ }^{2}$ Anesthesiology-Reanimatology Department, Pavlov First St. Petersburg State Medical University, Russia

"Corresponding author: Valery A. Voinov, Apheresis Therapy department, Pavlov First St. Petersburg State Medical University, Russia, Tel: 7-9119126502; E-mail: voinof@mail.ru

Received Date: August 28, 2018; Accepted Date: September 28, 2018; Published Date: October 05, 2018

Copyright: $\odot 2018$ VA Voinov et al. This is an open-access article distributed under the terms of the Creative Commons Attribution License, which permits unrestricted use, distribution, and reproduction in any medium, provided the original author and source are credited.

\begin{abstract}
Acute kidney injury is a serious complication of various inflammatory diseases of the abdominal and thoracic cavities, severe injuries and burns, eclampsia and sepsis, and a number of infectious diseases. Considering such a variety of etiologies there is a main pathogenesis feature, which is based on endoxemia with accumulation of a number of toxic products that cause disturbances in the vessels endothelium permeability with perivascular edema associated with decrease in the renal blood flow, glomerular filtration, tubular necrosis and oligo-anuria. The most common tactics of treatment is to perform kidney replacement therapy, mainly different methods of hemofiltration. However, not all toxic products are removed and the mortality rate remains quite high. The inclusion of hemosorption and plasmapheresis in the complex of therapeutic measures gives more favorable and stable results, showing a significant reduction of the mortality rate.
\end{abstract}

Keywords: Acute kidney injury; Endotoxicosis; Hemofiltation; Therapeutic apheresis; Plasma exchange; Hemosorbtion.

\section{Introduction}

The term "Acute Kidney Injury" (AKI) means inability of the kidneys to provide their excretory function leading to retention of nitrogenous waste products in the blood [1]. Acute renal failure quite often accompanies acute inflammatory organs diseases of the chest and abdomen cavities, severe injuries and burns, eclampsia and septic shock. The AKI incidence rates were 130-150 per 10,000/year, particularly among older people [2]. It is the main reason for multiple organ insufficiency and death rate up to $80 \%[3,4]$. All this indicates that the traditional treatment methods of acute renal failure using drugs and renal replacement therapy to be insufficient. The aim of this research is to study the possibilities of therapeutic apheresis in the treatment of AKI.

\section{Features of AKI pathogenesis}

AKI often develops on the background of acute pneumonia, which is to varying degrees accompanied by disorders of other vital organs, first of all, of the kidneys [5]. AKI is observed in one third of patients with respiratory distress syndrome [6]. It has long been observed that even in itself artificial lung ventilation, especially with a Positive EndExpiratory Pressure (PEEP) reduces renal blood flow by $32 \%$, glomerular filtration rate by $19 \%$, and urine output by $34 \%[7,8]$.

Often, AKI develops in the presence of sepsis or sepsis joins an already developed kidney disease [9-12]. Despite many clinical and fundamental studies giving a better understanding of the septic complications pathogenesis, the number of sepsis cases in the United States continues to increase, being the main cause of AKI and adverse outcomes [13]. Risk factors include severe burns, pancreatitis and peritonitis traumatic shock syndrome and prolonged compression ("crush syndrome"), eclampsia [14-16]. Mortality is as high as $70-80 \%$
[7,17]. This applies to AKI, which develops on the background of severe pancreatitis when $79 \%$ of patients have to resort to renal replacement therapy [18]. AKI also often accompanies acute liver failure with high mortality [19].

Nevertheless, considering a variety of etiological factors, the AKI pathogenesis is based on the renal parenchyma toxic damage. Disturbance of the vascular endothelium permeability leads to perivascular edema with decreased renal blood flow, glomerular filtration, tubular necrosis, oligoanuria [9]. According to the consensus reached at the conference of the working group on AKI (ADQI), the criteria for inclusion of patients to the "risk" group is decreased urine output-less than $0.5 \mathrm{~mL} / \mathrm{kg}$ in $6 \mathrm{~h}$, to the "injury" group-less than 0.5 $\mathrm{mL} / \mathrm{kg}$ in $12 \mathrm{~h}$, to the "failure" group-less than $0.3 \mathrm{~mL} / \mathrm{kg}$ in $24 \mathrm{~h}$ or anuria in $12 \mathrm{~h} \mathrm{[20].} \mathrm{In} \mathrm{the} \mathrm{"risk"} \mathrm{group} \mathrm{the} \mathrm{risk} \mathrm{of} \mathrm{death} \mathrm{is} 13 \%$, in the "disease" group -40\%, and in the "failure" group-80\% [3].

\section{Possibilities of kidney replacement therapy}

Such unfavorable predictions for ARF, of course, require intensive therapy. But, given the absence of any specific medication, the most common method to correct renal excretory dysfunction is to remove the accumulating fluid by hemodialysis or various methods of hemofiltration [13,21-24].

This approach is explained by the desire to eliminate only visible disorders-fluid retention during AKI. But it is actually a symptomatic therapy that does not affect the essence of the pathology-endotoxicosis, underlying these organ disorders. Indeed, the mortality rate in such patients remained high enough-up to $50-70 \%$, regardless of the "renal replacement therapy" methods choice - dialysis, intermittent or permanent veno-venous hemofiltration [24-27]

Hemofiltration is also ineffective when the liquid volumes accumulation is more than $20 \%$ of the body weight [28]. AKI also develops in children when using hemofiltration, the death rate reaches $50 \%$, and in hematological patients with bone marrow transplantation 
Page 2 of 4

it reaches $100 \%$ [29]. Moreover, the danger is not only in high mortality, but also in long-term disability with chronic renal failure [30].

But prospectively, the survivors often show signs of chronic renal failure [22,31]. In spite of the applied methods of renal replacement therapy (continuous or intermittent hemofiltration), after discharge from hospitals the mortality rate during the first year was $23 \%$ and in the second year-7.6\%, which was $65.7 \%$ in total [32]. This was also confirmed in later studies $[33,34]$. Using only hemofiltration we cannot remove macromolecular and other toxic products, including fibrinogen, which causes the need to use plasmapheresis [35]. This confirms our belief that purely symptomatic therapy (removal of the excess fluid) does not eliminate the problem of endotoxemia, which is the major tanatogenesis factor.

In particular, at high level of cytokines removal such as TNF- $\alpha$, IL-1 $\beta$, other cytokines IL- 6 and IL-8, which are more unfavorable in prognosis, were retained in the body noted that using hemodiafiltration can reduce the levels of TNF- $\alpha$, IFN- $\alpha$ and IL- 4 with correction of critical states course; however, such a procedure did not influence the course of infection. The latter responded to correction only using plasmapheresis that contributed to restoration of decreased production of INF- $\alpha$ and improvement of cellular and humoral immunity [36]. A combination of plasmapheresis with continuous hemofiltration is used though; it seems that it is the plasma exchange that played more essential role here [37].

\section{Observations}

We have experience in treating 164 patients who were treated in the intensive care unit of the surgical clinic at the I.P. Pavlov First St. Petersburg State Medical University. The most common types of pathology were septic inflammatory complications in abdominal and thoracic surgery (destructive pancreatitis, peritonitis, acute pneumonia and lung abscesses). The severity of the patients' condition was taken into account according to the classification of Bellomo et al. (2004) and considering the levels of medium-molecular oligopeptides [38], in the norm of $240.4 \pm 14.2$ Units (Table 1).

\begin{tabular}{|l|l|l|}
\hline $\begin{array}{l}\text { AKI } \\
\text { severity } \\
\text { group }\end{array}$ & AKI Criteria (diuresis) & $\begin{array}{l}\text { Medium-molecular } \\
\text { oligopeptides level (Units) }\end{array}$ \\
\hline "Risk" & Less than $0.5 \mathrm{~mL} / \mathrm{kg}$ in $6 \mathrm{~h}$ & $350.0 \pm 22.5$ \\
\hline Injury & Less than $0.5 \mathrm{~mL} / \mathrm{kg}$ in $12 \mathrm{~h}$ & $644.2 \pm 45.3$ \\
\hline Failure & $\begin{array}{l}\text { Less than } 0.3 \mathrm{~mL} / \mathrm{kg} \text { in } 24 \mathrm{~h} \text { or } \\
\text { anuria in } 12 \mathrm{~h}\end{array}$ & $880.1 \pm 52.6$ \\
\hline
\end{tabular}

\section{Table 1: AKI Severity Classification.}

Table 1 shows that AKI severity is clearly correlated with the level of medium-molecular oligopeptides and this indicator reflects the patient's condition dynamics during the treatment. This shows the role of endotoxicosis in the genesis of acute kidney lesions.

Three groups of patients were identified depending on the AKI severity: "Risk", "Injury" and "Failure" groups, using only traditional medical therapy with artificial ventilation of the lungs (67), Extracorporeal Detoxification-Plasma Exchange or hemosorption (97) and extracorporeal membrane oxygenation (ECMO) with hemosorption (in this analysis only 11 patients included from the "failure" group, who underwent ECMO with hemosorption) (Table 2).

\begin{tabular}{|l|l|l|l|l|}
\hline $\begin{array}{l}\text { AKI } \\
\text { severity } \\
\text { group }\end{array}$ & $\begin{array}{l}\text { Traditional } \\
\text { treatment }\end{array}$ & $\begin{array}{l}\text { Hemosorption I I } \\
\text { plasma } \\
\text { exchange }\end{array}$ & $\begin{array}{l}\text { ECMO } \\
\text { hemosorption }\end{array}$ & $\begin{array}{l}\text { Total no of } \\
\text { patients }\end{array}$ \\
\hline "Risk" & 52 & 47 & - & 99 \\
\hline Injury & 15 & 39 & - & 54 \\
\hline Failure & - & - & 11 & 11 \\
\hline Total & 67 & 86 & 11 & 164 \\
\hline
\end{tabular}

Table 2: Treatment methods depending on AKI severity (number of patients).

In the "Risk" group there were no lethal outcomes, but the average duration of treatment with extracorporeal detoxification was $28.0 \pm 1.5$ days, while using only traditional therapy- $40.3 \pm 3.3$ days. In the "Injury" group, when using extracorporeal detoxification methods, the mortality rate was $31.03 \%$, while using only traditional therapy-73.33\%. Even in the "Failure" group the mortality rate was only $36.3 \%$, while such patients are usually doomed.

There was a notable case of a patient treated for an advanced anury associated with eclampsia lasting for a month after the delivery. Following hemosorption procedure on the next day diuresis was already $500 \mathrm{~mL}$, and after a repeated procedure it was restored completely resulting in fast recovery of the patient.

\section{Discussion}

It should be noted that the very development of acute infectious process could be due to initial immunodeficiency, developed as a result of other recent diseases (even conventional respiratory viral infections), adverse environmental or social factors, and chronic intoxication. Further develops a chain mutually aggravating events. The immune system mobilizes all its reserves to fight infectious and other agents but these reserves are not unlimited and eventually become exhausted. The increase of endotoxicosis acts overwhelmingly on all cellular and humoral immunity components, leading to an even deeper immunosuppression, which can be described as "immune distress syndrome".

Thus, septic complications develop as a severe endotoxicosis on the background of increasing immunosuppression, resulting in a vicious circle, which neither the body nor the most intensive drug therapy is able to break.

Sorption methods are based on such feature of many harmful products as the presence of charge of these molecules or free radicals in their structure, which in contact with the sorbent consisting of activated carbon or other surfactants (sometimes coated with enzymes or ion exchange resins), are able to be adsorbed to the latter. Hemosorption can remove not only toxic metabolites but also circulating in the blood living or already killed pathogens by antibiotics, which was confirmed by our special studies [39].

However, the immune system remains depleted. And here plasma exchange comes forward. Replacement of the removed plasma with fresh frozen donor plasma enables to quickly restore the natural defense mechanisms, without which the most powerful antibiotics of the ultra-wide spectrum are useless, and their hepatotoxicity or 
nephrotoxicity can further aggravate the patient's condition. The guidelines of the American Society for Apheresis (ASFA) for 2016 also contain recommendation to use plasmapheresis in sepsis associated with multiple organ failure [40]. After massive plasma exchange a faster turning point of the disease occurs that reverses the development of the organ disorders.

Of course, the presence of concomitant acute renal failure with diuresis decrease down to anuria may justify the use of filtration methods to remove excess fluid, but this does not provide restoration of the kidneys own excretory function. It should be taken into account that hemofiltration does not remove all the pathological products, many of which have a large molecular weight.

Using hemofiltration only it is impossible to remove toxic largemolecular products, including fibrinogen, which even during hemofiltration makes us resort to plasmapheresis or hemosorption $[35,41]$. Severe poisoning has been observed in some countries of Western Europe in the summer of 2011, caused by serotype O104:H4 Escherichia coli. The secreted Shiga-toxin caused severe enterocolitis followed by development of hemolytic uremic syndrome and AKI with high level of mortality. Antibiotics in this case were useless or, on the contrary, contributed to increase of endotoxicosis. It became clear only in the end of this epidemic that forced to refuse from antibiotic therapy. Use of plasma exchange in the early stages of the disease provided fast healing [42-46].

Treatment of victims in the aero-mobile hospital of EMERCOM, Russia, being in places of technogenic and natural catastrophes proves to be indicative. In cases of "crash syndrome" AKI inevitably develops. However, immediate use of plasmapheresis within two hours after the victims extracted from the rubble excluded the need to conduct renal replacement therapy [47-48].

The findings presented quite convincingly show feasibility of a more complete active detoxification therapy-hemosorption or plasmapheresis. And indeed, almost always after the "toxic burden" removal from the kidneys their excretory function was restored. The next day diuresis was not less than 500-700 mL. It was associated with improved functional status of the other vital organs such as lungs, liver, heart, and brain $[49,50]$. This confirms our belief that purely symptomatic therapy (removal of excess fluid) does not eradicate the problem of endotoxicosis, which is the main factor of tanatogenesis.

\section{Conclusion}

The presented findings confirm the leading role of endotoxemia in the genesis of AKI, which makes it necessary to perform more complete detoxification therapy. Without diminishing the value of hemofiltration, inclusion of hemosorption and plasmapheresis in the treatment will help influence all the parts of the pathological process and achieve better and more stable results of AKI treatment.

\section{References}

1. Bindroo S, Challa HJ (2018) Renal Failure. StatPearls [Internet]. Treasure Island (FL): StatPearls Publishing, Aug 1.

2. Sawney S, Robinson HA, Van der veer SN, Hounkpatin HO, Scale TM, et al. (2018) Acute kidney injury in the UK: A replication cohort study of the variation across three regional populations. BMJ Open 8: e019435.

3. Steinvall I, Bak Z, Sjoberg F (2008) Acute kidney injury is common, parallels organ dysfunction or failure, and carries appreciable mortality in patients with major burns: A prospective exploratory cohort study. Crit Care 12: 124-127
4. Pakula AM, Skinner RA (2016) Acute kidney injury in the critically ill patient: A current review of the literature. J Intensive Care Med 31: 319-324.

5. Bolton WK (2010) Pulmonary Renal Syndrome and Emergency Therapy. Contrib Nephrol 165: 166-173.

6. Murugan R, Karajala-Subramanyam V, Lee M, Yende S, Kong L, et al. (2010) Acute kidney injury in non-severe pneumonia is associated with an increased immune response and lower survival. Kidney Int 77: 527-535.

7. Ko GJ, Rabb H, Hassoun HT (2009) Kidney-lung crosstalk in the critically ill patient. Blood Purif 28: 75-83.

8. Koyner JL, Murray PT (2010) Mechanical ventilation and the kidney. Blood Purif 29: 52-68.

9. Bougle A, Duraneau J (2011) Pathophysiology of sepsis-induced acute kidney injury: The role of global renal blood flow and renal vascular resistance. Contrib Nephrol 174: 89-97.

10. Mehta RL, Bouchard J, Soroko SB, Ikizler TA, Paganini EP, et al. (2011) Sepsis as a cause and consequence of acute kidney injury: Program to improve care in acute renal disease. Intensive Care Med 37: 241-248.

11. Billups KB, Reed EE, Phillips DS, Stevenson KB, Steinberg SM et al. (2018) Risk of acute kidney injury in critically ill surgical patients with presumed pneumonia is not impacted by choice of meticillin-resistant staphylococcus aureus therapy. Int J Crit Illn Inj Sci 8: 22-27.

12. Peters E, Antonelli M, Wittebole X, Nanchal R, François B et al. (2018) A worldwide multicentre evaluation of the influence of deterioration or improvement of acute kidney injury on clinical outcome in critically ill patients with and without sepsis at icu admission: Results from the intensive care over nations audit. Crit Care 22: 188.

13. Ueno $\mathrm{T}$ (2017) The roles of continuous renal replacement therapy in septic acute kidney injury. Artif Organs 41: 667-672.

14. Mosier MJ, Pham TN, Klein M, Gibran NS, Arnoldo BD et al. (2010) Early acute kidney injury predicts progressive renal dysfunction and higher mortality in severely burned adults. J Burn Care Res 31: 83-92.

15. Serov VN, Vetrov VV, Voinov VA (2011) Preeclampsia. Saint Petersburg, JSC Alina Firm: 300 p.

16. Safari S, Hashemi B, Forouzanfar MM, Shahhoseini M, Heidari M (2018) Epidemiology and outcome of patients with acute kidney injury in emergency department; A cross-sectional study. Emerg (Tehran) 6: e30.

17. Chou Y-H, Huang T-M, Wu VC, Wang CY, Shiao CC et al. (2011) Impact of timing of renal replacement therapy initiation on outcome of septic acute kidney injury. Crit Care 15: R134.

18. Naqvi R (2018) Acute kidney injury in association with acute pancreatitis. Pak J Med Sci 34: 606-609.

19. Chen N, Chen X, Ding X, Teng L (2018) Analysis of the high incidence of acute kidney injury associated with acute-on-chronic liver failure. Hepatol Int 12: 262-268.

20. Bellomo R, Ronco C, Kellum JA (2004) Acute renal failure - definition, outcome measures, animal models, fluid therapy and information technology needs: The second international consensus conference of the acute dialysis quality initiative (ADQI) group. Crit Care 8: R204-212.

21. Abe M, Okada K, Suzuki M, Matsumoto S, Maruyama T et al. (2010) Comparison of sustained hemodiafiltration with continuous venovenous hemodiafiltration for the treatment of critically ill patients with acute kidney injury. Artif Organs 34: 331-338.

22. Chawla LS (2011) Acute kidney injury leading to chronic kidney disease and long-term outcomes of acute kidney injury: The best opportunity to mitigate acute kidney injury? Contrib Nephrol 174: 182-190.

23. Claure-Del Granado R, Macedo E (2018) Indications and Timing of Renal Replacement Therapy. Gac Med Mex 154: S15-S21.

24. Negi S, Koreeda D, Kobayashi S, Yano T, Tatsuta K et al. (2018) Acute kidney injury: Epidemiology, outcomes, complications, and therapeutic strategies. Semin Dial 31: 519-527

25. House AA, Ronco C (2008) Extracorporeal blood purification in sepsis and sepsis-related acute kidney injury. Blood Purif 26: 30-35. 
26. Palevsky PM, Zhang JH, O'Connor TZ, Chertow GM, Crowley ST (2008) Intensity of renal support in critically ill patients with acute kidney injury. N Engl J Med 359: 7-20.

27. Palevsky PM, O’Connor TZ, Chertow GM, Crowley ST, Zhang JH et al. (2009) Intensity of renal replacement therapy in acute kidney injury: perspective from within the acute renal failure trial network study. Crit Care 13: 310-314.

28. Sutherland SM, Zappitelli M, Alexander SR, Chua AN, Brophy PD et al. (2010) Fluid overload mortality in children receiving continuous renal replacement therapy: The prospective pediatric continuous renal replacement therapy registry. Am J Kidney Dis 55: 316-325.

29. Al-Ayed T, Rahman NU, Alturki A, Aljofan F (2018) Outcome of continuous renal replacement therapy in critically ill children: a retrospective cohort study. Ann Saudi Med 38: 260-268.

30. Basu RK (2018) Acute kidney injury in hospitalized pediatric patients. Pediatr Ann 47: e286-e291.

31. Geri G, Stengel B, Jacquelinet C, Aegerter P, Massy ZA et al. (2018) Prediction of chronic kidney disease after acute kidney injury in icu patients: study protocol for the PREDICT multicenter prospective observational study. Ann Intensive Care 8: 77.

32. Van BA, Elseviers MM, Lins RL, SHARF Study Group (2010) Outcome of acute kidney injury with different treatment options: Long-term followup. Clin J Am Soc Nephrol 5: 1755-1762.

33. Oeyen S, De Corte W, Benoit D, Annemans L, Dhondt A et al. (2015) Long-term quality of life in critically ill patients with acute kidney injury treated with renal replacement therapy: A matched cohort study. Crit Care 19: 289.

34. De Corte W, Dhondt A, Vanholder R, De Waele J, Decruyenaere J et al (2016) Long-term outcome in icu patients with acute kidney injury treated with renal replacement therapy: A prospective cohort study. Crit Care 20: 256 .

35. Fulop T, Cosmin A, Juncos LA (2011) Recurring extracorporeal circuit clotting continuous renal replacement therapy resolved after singlesession therapeutic plasma exchange. J Clin Apher 26: 214-215.

36. Karaskov AM, Mukaetova TV, Lomivorotov VN, Sennikov SV (2002) Kinetics of cytokine profile in the treatment of multiple organ failure a continuous hemofiltration and plasmapheresis. Proc. X Conf Moscow Society of Hemapheresis-Moscow: 97.

37. Schmidt J, Mann S, Mohr VD, Lampert R, Firla U, et al. (2000) Plasmapheresis combinated with continuous venovenous hemofiltration in surgical patients with sepsis. Int Care Med 26: 532-537.
38. Gabrielyan NI, Dmitriyev AA, Savostyanova OA, Kizhayeva ES (1985) Average Molecules and Level of Endogenous Intoxication at Resuscitation Patients. Anest Reanimatol (Rus) 1: 36-38.

39. Voinov VA. (2016) Therapeutic Apheresis / Constanta: Celebris: 400 p.

40. Schwartz J, Panmanabhan A, Aqui N Baljgun R, Connelly-Smith L et al. (2016) Sepsis with multiorgan failure. guidelines on the use of therapeutic apheresis in clinical practice - Evidence-based approach from the writing committee of the American Society for apheresis: The seventh special issue. J Clin Apher 31: 303-304.

41. Winchester JF, Kellum JA, Ronco C (2003) Sorbents in acute renal failure and systemic inflammatory response syndrome. Blood Purif 21: 79-84.

42. Colic E, Dieperink H, Titlestad K, Tepel M (2011) Management of an acute outbreak of diarrhoea-associated haemolytic uraemic syndrome with early plasma exchange in adults from southern Denmark: An observational study. Lancet 78: 1089-1093.

43. Keir LS, Marks SD, Kim JJ (2012) Shigatoxin-associated hemolytic uremic syndrome: Current molecular mmechanisms and future therapies. Drug Des Devel Ther 6: 195-208.

44. Ulrich S, Bremer P, Neuman-Grutzeck C, Otto H, Ruther C, et al. (2013) Symptoms and clinical course of EHEC O104 infection in hospitalized patients: A prospective single center study. PLoS One 8: e55278.

45. Van Gemert LM, Montemayor-Garcia C, Rose WN (2014) Dramatic improvement immediately after plasma exchange in a patient with shiga toxin-producing Escherichia coli hemolytic uremic syndrome. J Clin Apher 29: 46.

46. Loos S, Aulbert W, Hoppe B, Ahlenstiel-Grunow T, Kranz B, et al. (2017) Intermediat follow-up of pediatric patients with hemolytic uremic syndrome during the 2011 outbreak caused by E. coli O104:H4. Clin Infect Dis 64: 1637-1643.

47. Popov AS, Loginov SP, Obrastzov NL, Skorobulatov AV (2007) Membrane plasmapheresis in complex therapy of injured with crash syndrome at the stages of evacuation in the conditions of airmobile hospital of EMERCOM of Russia. Anesthesiology and Reanimatology (Moscow) 4: 28-30.

48. Popov AS (2011) Application membrane plasmapheresis during liquidation of medical and sanitary consequences of emergency situations. Efferent and physico-chemical medicine (Moscow) 4: 27-30.

49. Voinov VA (2012) Plasmapheresis in the treatment of acute pancreatitis. Efferent and physical-chemical medicine (Moscow) 2:14-16.

50. Voinov VA (2013) Tactics of apheresis therapy in sepsis. Vestnik Hirurgii (Rus) 172: 74-77. 